\title{
Clinical and laboratory evaluation of a real-time PCR for Clostridium difficile toxin $\mathrm{A}$ and $\mathrm{B}$ genes
}

\author{
E. de Jong • A. S. de Jong • C. J. M. Bartels • \\ C. van der Rijt-van den Biggelaar • W. J. G. Melchers • \\ P. D. J. Sturm
}

Received: 21 October 2011 /Accepted: 12 January 2012 / Published online: 14 February 2012

(C) The Author(s) 2012. This article is published with open access at Springerlink.com

\begin{abstract}
Many laboratories use enzyme immunoassays (EIAs) for the diagnosis of Clostridium difficile infection (CDI). More recently, polymerase chain reaction (PCR)based diagnosis has been described as a sensitive test. Real-time PCR for the detection of $C$. difficile toxin A and $\mathrm{B}$ genes was evaluated. A prospective evaluation was performed on stool samples from 150 hospitalized adult patients and 141 healthy volunteers. PCR was compared to toxigenic culture (TC), direct cytotoxicity test (CTT), ImmunoCard ${ }^{\circledR}$ Toxin A and B (Meridian Bioscience), and enzyme-linked immunosorbent assay (ELISA) (Vidas). The results were correlated with clinical data using a standardized questionnaire. The diagnostic yield of the PCR was further evaluated after implementation. Using toxigenic culture as the gold standard, the sensitivity and specificity of PCR were 100 and $99.2 \%$, respectively. Patients were categorized as follows: TC/PCRpositive $(n=17)$ and negative TC $(n=133)$. The differences in these groups were more frequent use of antibiotics and leukocytosis $(p<0.05)$. The diagnostic yield of PCR was evaluated during a period of 6 months and showed an increase of positive patients by $50 \%$. PCR for the detection of toxigenic $C$. difficile has a high sensitivity and can rule out CDI, but cannot differentiate CDI from asymptomatic carriage. Clinicians should be aware of this
\end{abstract}

E. de Jong $\cdot$ A. S. de Jong $\cdot$ C. J. M. Bartels

C. van der Rijt-van den Biggelaar - W. J. G. Melchers •

P. D. J. Sturm $(\square)$

Department of Medical Microbiology,

Radboud University Nijmegen Medical Centre,

P.O. Box 9101, 6500 HB Nijmegen, Netherlands

e-mail: P.Sturm@mmb.umcn.nl in order to prevent inappropriate treatment and delay of other diagnostics.

\section{Introduction}

The laboratory diagnosis of Clostridium difficile infection (CDI) is based on the demonstration of toxin $\mathrm{A} / \mathrm{B}$ directly in stool samples or in culture after isolation of the pathogen. The direct cytotoxicity test (CTT) has been the gold standard in laboratory diagnosis; more recently, toxigenic culture (TC) has been used for this purpose [1]. Both methods are not suitable for routine diagnosis since results are delayed (at least to more than $24 \mathrm{~h}$ ), they are laborintensive, and fresh cell cultures are needed. To overcome these problems, numerous enzyme immunoassays (EIAs) have been developed which are now used widely in clinical laboratories [2]. However, the described performance of EIAs varies widely, with sensitivity and specificity ranging from 23 to $99 \%$ and 70 to $100 \%$, respectively [3-9]. More recently, polymerase chain reaction (PCR) has been studied in the diagnosis of CDI $[8,10-13]$. A number of studies demonstrate that PCR is a sensitive diagnostic test. The reported specificities range between 94 and $99.2 \%$, which may result from the lower sensitivity of the gold standard, a common problem in the evaluation of the highly sensitive PCR-based methods. Furthermore, asymptomatic carriage of toxigenic $C$. difficile has been described in $0.5-13 \%$ of adults and may be of concern to the use of PCR.

In the current prospective study, PCR was compared to TC, CTT, and two EIAs for the routine diagnosis of CDI. In contrast to published PCR studies, our test results were correlated to clinical presentation and follow-up. To estimate the 
potential problem of asymptomatic carriage, PCR was performed in healthy volunteers.

\section{Materials and methods}

Setting and specimens

The study was performed in a tertiary teaching hospital with approximately 30,000 patient admissions annually. Initial PCR evaluation was performed on 45 culture-positive stool samples. Thereafter, consecutive stool specimens that were submitted to the routine clinical microbiology laboratory for C. difficile toxin detection were collected prospectively from 150 hospitalized adult patients. Only one specimen per patient was included. No outbreaks of diarrheal pathogens were recorded by the hospital infection control unit of our hospital in the study period.

Upon receipt at the laboratory, the routinely used diagnostic ImmunoCard ${ }^{\circledR}$ Toxin $A$ and $B$ test (ICTAB) was performed and four aliquots of the stool specimen were stored at $-80^{\circ} \mathrm{C}$ for subsequent testing in batch by TC, PCR, CTT, and enzyme-linked immunosorbent assay (ELISA).

To correlate test results with clinical presentation, clinical data on signs and symptoms were collected. To assess the occurrence of asymptomatic carriage, healthy adult volunteers were recruited among medical students and hospital employees. Volunteers were informed on the purpose of the study and that the results would not be reported. Exclusion criteria for volunteers were the use of antibiotics or complaints of diarrhea. All specimens were thawed only once before testing in batch. Specimens from all volunteers were tested by TC and PCR, and positive specimens were further tested using ICTAB, ELISA, and CTT.

The study was approved by the hospital ethics committee.

Routinely used enzyme immunoassay (ICTAB)

The routinely used diagnostic ICTAB test ImmunoCard ${ }^{\circledR}$ (Meridian Bioscience, Cincinnati, OH, USA) was performed following the manufacturer's instructions. The results were interpreted independently by two technicians.

\section{Toxigenic Culture (TC)}

C. difficile selective agar with cefoxitin, amphotericin B and cycloserine (CLO, bioMérieux), and Columbia blood agar with colistin and nalidixic acid (CAP, Oxoid, Cambridge, UK) were inoculated with $10 \mu \mathrm{l}$ of the stool specimen. The media were incubated for 5 days under anaerobic conditions at $37^{\circ} \mathrm{C}$. Colonies with growth characteristics of C. difficile were investigated by sequence analysis of the $16 \mathrm{~S}$ rRNA for identification [14]. C. difficile isolates were subcultured in brain heart infusion (BHI, CM0225, Oxoid) for the detection of toxin production using the cytotoxicity test and PCR detecting genes encoding for toxin $\mathrm{A}$ and $\mathrm{B}$.

Ribotyping was performed on all isolates by the National Reference Laboratory for Clostridium difficile.

\section{Direct cytotoxicity test (CTT)}

The CTT was used to determine the presence of toxin in stool samples (direct CTT) and toxin production in C. difficile isolates (TC).

The supernatant of $1 \mathrm{mg}$ stool suspended in $1 \mathrm{ml}$ phosphate buffered saline (PBS) was filtered through a $0.45-\mu \mathrm{M}$ filter (Millipore ${ }^{\circledR}$, Billerica, MA, USA). Quantities of $20 \mu \mathrm{l}$ of filtrate and $20 \mu \mathrm{l}$ of filtrate with $20 \mu \mathrm{l}$ of anti-C. sordellii antitoxin (SAT, Uniprom, T5000, Krimpen aan de IJssel, the Netherlands) were incubated on Vero cells for $48 \mathrm{~h}$ at $37^{\circ} \mathrm{C}$. Appropriate controls were included with each micro-titer plate used, i.e., $20 \mu \mathrm{l}$ of toxin (C. difficile Bess strain), $20 \mu \mathrm{l}$ of SAT, and $20 \mu \mathrm{l}$ toxin with $20 \mu \mathrm{l}$ SAT. The specimen was positive if $50 \%$ of the cells showed a characteristic cytopathic effect (cell rounding) which was neutralized by SAT.

The cytotoxicity of the isolates was tested as described above using a $25-\mu \mathrm{l}$ aliquot of BHI after filtering through a $0.45-\mu \mathrm{M}$ filter.

\section{PCR}

DNA extraction: $200 \mu \mathrm{l}$ supernatant of a $10 \%$ fecal suspension in PBS was used for DNA isolation on MagNA Pure LC using the MagNA Pure LC Total Nucleic Acid Isolation Kit (Roche Diagnostics, Almere, the Netherlands). For PCR on cultured bacteria, a single colony was boiled for $10 \mathrm{~min}$ in $50 \mu \mathrm{l}$ of glycerol broths. Quantities of $5 \mu \mathrm{l}$ of the prepared DNA were used for the PCR reactions.

Real-time PCR assay: a triplex real-time PCR assay was developed to simultaneously detect the $C$. difficile $t c d A$ and $t c d B$ toxin genes and the $g B$ polymerase gene of phocine herpes virus (PhHV-1), which served as the internal control [15]. A positive PCR result did not distinguish between the presence of the toxin $\mathrm{A}$ and/or $\mathrm{B}$ gene; $t c d A$ primers and probes were adapted from Bélanger et al.[16], i.e., the antisense molecular beacon was replaced by a sense TaqMan probe (5'-CTACTAgAggAAgAgATTCAAAATCCTCA$\left.3{ }^{\prime}\right) ; t c d B$ and $\mathrm{PhHV}$ primers and probes were as described $[12,15]$. PCR mixes consisted of $25 \mu 1$ of $2 \times$ LC480 Probes Master (Roche Diagnostics, Almere, the Netherlands), $0.5 \mu \mathrm{M}$ of each primer and $0.1 \mu \mathrm{M}$ of each probe, and $5 \mu \mathrm{l}$ of extracted DNA. Real-time PCR was performed on a Roche LC480. 
DNA sequencing for confirmation of the identification of C. difficile: 16S rRNA gene sequences were determined using primers described by Weisburg et al. [14]. All DNA sequences were determined using a BigDye Terminator version v3.1 cycle sequencing kit (ABI) and an ABI 3100 DNA sequencer.

\section{ELISA}

The VIDAS CDAB test (biomérieux, Marcy-l'Etoile, France), an ELISA for the detection of toxin A and B, was performed according to the manufacturer's instructions. All stool samples were tested in batch by one technician.

\section{Clinical evaluation}

Demographic data and laboratory results were collected from the electronic patient files. Patients' medical history and current signs and symptoms were collected by interviewing the attending physician and reviewing the medical charts using a standardized questionnaire. Data collected included reason for and duration of admission, characteristics of the current episode of diarrhea (consistency, frequency, duration, and abdominal pain), C-reactive protein (CRP) and white blood cell count (WBC), use of antibiotics in the previous 3 months, and the presence of other risk factors for $C$. difficile infection (prior hospitalization, use of immunosuppressive medication, proton pump inhibitors, gastric tube feeding, chemotherapy, abdominal surgery).

The clinical course was evaluated retrospectively in patients who were negative by ICTAB but were positive by PCR in order to investigate the clinical significance of these positive results.

\section{Diagnostic yield after implementation of the PCR}

The results of $C$. difficile detection in routine clinical specimens were extracted from the laboratory information system for the first 6 months after implementation of the PCR and compared to the results obtained in the 6 months prior to implementation of the PCR when laboratory diagnosis was based toxin detection using ICTAB. All PCR-positive specimens were cultured as described above.
Statistical analysis

The Chi-squared test and Fisher's exact test were used to analyze the significance of clinical parameters.

\section{Results}

All of the 45 culture-positive stool samples from the initial evaluation were positive on PCR testing.

A total of 150 patients were included during a 2-month period, of which $49.7 \%$ were male and the median age was 61 years (range 19-95). Most patients were admitted to the medical wards (56\%), followed by the surgical $(20.7 \%)$ and hematology/oncology wards (20.7\%) and the intensive care units $(2.6 \%)$.

Using the TC as the gold standard, the sensitivity, specificity, positive predictive value (PPV), and negative predictive value (NPV) of the PCR, ICTAB, ELISA, and CTT are shown in Table 1.

TC was positive in 17 patients (11\%). PCR was positive in 18 patients, including all 17 TC-positive patients, as well as one patient with negative results for all other tests and repeated negative stool cultures. CTT was positive in 12 patients, all of whom had a positive TC. The routinely used ICTAB was positive in nine patients; eight of these patients had a positive TC. The ELISA was positive in 16 patients, but only ten of these had a positive TC. Equivocal ELISA results were found in five patients, and three of these had a positive TC. Respectively, 5, 9, and 4 patients with a positive TC were negative using CTT, ICTAB, and ELISA. An overview of all the test results is presented in Table 2.

The isolates belonged to the following ribotypes: ICTABpositive: 001, 011, 014, 018, 053, 056, and 078; ICTABnegative: 001, 002, 014, 046, 079, 165, and two unknown. Two ICTAB-negative but TC- and PCR-positive specimens contained the ribotypes known to cause false-negative ICTAB results.

According to the laboratory findings, the patients were categorized in patients with a positive TC $(n=17)$, of which five had a negative CTT, and a negative TC $(n=133)$. Patient characteristics and clinical data were compared in these patient categories (Table 3). More prior antibiotic use and a higher occurrence of elevated WBC was present in patients with a positive TC $(p<0.05)$. Within the group of
Table 1 Sensitivity, specificity, positive predictive value (PPV), and negative predictive value (NPV) using toxigenic culture (TC) as the gold standard

\begin{tabular}{lllll}
\hline & Sensitivity & Specificity & PPV & NPV \\
\hline Polymerase chain reaction (PCR) & $100 \%$ & $99.2 \%$ & $94.4 \%$ & $100 \%$ \\
Direct cytotoxicity test (CTT) & $70 \%$ & $100 \%$ & $100 \%$ & $96.3 \%$ \\
ImmunoCard® Toxin A and B (ICTAB) & $47 \%$ & $99.2 \%$ & $88.9 \%$ & $93.6 \%$ \\
Enzyme-linked immunosorbent assay (ELISA) & $58.8 \%$ & $89.4 \%$ & $62.5 \%$ & $96.7 \%$ \\
\hline
\end{tabular}


Table 2 Test results for the different tests in 150 patients

\begin{tabular}{llllll}
\hline Number of patients & TC & PCR & CTT & ICTAB & ELISA \\
\hline 7 & + & + & + & + & + \\
2 & + & + & + & - & + \\
3 & + & + & + & - & Eq \\
1 & + & + & - & - & + \\
3 & + & + & - & - & - \\
1 & + & + & - & + & - \\
1 & - & + & - & - & - \\
1 & - & - & - & + & - \\
6 & - & - & - & - & + \\
2 & - & - & - & - & Eq \\
$123^{\text {a }}$ & - & - & - & - & - \\
\hline
\end{tabular}

${ }^{\text {a }}$ Four patients had a non-toxigenic strain

Eq: equivocal on repeated testing

patients with positive TC, no differences were found between patients with positive ( $n=12)$ and negative CTT $(n=5)$; however, the number of patients was low. There was only one patient with a positive PCR only.

The median cycling time (CT) value of PCR was 26.44 (range 21.58-34.69) for CTT-positive stool samples, 38.15 (range 25.51-38.36) for CTT-negative stool samples, and 36.32 for the TC/CTT-negative stool sample.

The clinical course was investigated retrospectively in ten patients who were not diagnosed by our routinely used ICTAB (Table 4), i.e., nine patients with positive TC and PCR, and one patient with a positive PCR only. Five of these patients also had a positive CTT. One of these patients (patient 5, Table 4) was diagnosed with pseudomembranous colitis (PMC) by endoscopic evaluation, and one patient (patient 2) was clinically diagnosed with CDI despite the negative laboratory result. Both patients recovered with metronidazole therapy. One patient (patient 1) recovered after the treatment of graft-versus-host disease (GVHD), which was diagnosed by the histological examination of colon biopsies, and in the two other patients (patients 3 and 4), symptoms resolved within 2 days without treatment, despite the continuation of antibiotic therapy.

Four patients had a positive TC and PCR but negative CTT. One patient (patient 6) was diagnosed with GVHD by the histology of colon biopsies and died because of extensive disease. One patient (patient 7) had severe diarrhea and recovered from recurrent episodes of diarrhea in a timescale of several months without intervention. One patient (patient 8) recovered within two days without intervention. One patient (patient 9) was admitted with diarrhea after antibiotic treatment and recovered with calcium supplements for hemodialysis treatment. The patient with a positive PCR (patient 10) only developed recurrent episodes of diarrhea during multiple
Table 3 Patient characteristics and clinical data of patients with positive and negative TC

\begin{tabular}{lll}
\hline & TC-positive $(n=17)$ & TC-negative $(n=133)^{\mathrm{a}}$ \\
\hline Fever $>38.5^{\circ} \mathrm{C}$ & $5 / 16(31 \%)$ & $50 / 127(39 \%)$ \\
Diarrhea & & \\
$>48$ h & $9 / 17(53 \%)$ & $64 / 133(49 \%)$ \\
$>24 \mathrm{~h}$ & $2 / 17(11 \%)$ & $23 / 133(17 \%)$ \\
No & $6 / 17(36 \%)$ & $46 / 133(34 \%)$ \\
Abdominal pain & $7 / 16(44 \%)$ & $33 / 127(26 \%)$ \\
Antibiotics & & \\
In prior 3 months & $16 / 17(94 \%)^{\mathrm{b}}$ & $84 / 131(64 \%)^{\mathrm{b}}$ \\
No & $1 / 17(6 \%)$ & $47 / 131(36 \%)$ \\
Gastric tube feeding & $3 / 17(18 \%)$ & $27 / 133(20 \%)$ \\
Chemotherapy & $2 / 17(12 \%)$ & $21 / 133(16 \%)$ \\
Prior CDI & $2 / 17(12 \%)$ & $5 / 133(4 \%)$ \\
Proton pump inhibitor & $8 / 17(47 \%)$ & $50 / 133(38 \%)$ \\
Immunocompromised & $7 / 17(42 \%)$ & $62 / 133(47 \%)$ \\
Ward & & \\
Medical & $8 / 17(47 \%)$ & $76 / 133(57 \%)$ \\
Surgical & $6 / 17(35 \%)$ & $25 / 133(19 \%)$ \\
ICU & $0 / 17$ & $4 / 133(3 \%)$ \\
Hematology/oncology & $3 / 17(18 \%)$ & $28 / 133(21 \%)$ \\
WBC & & \\
$>15 \times 10^{9} / 1$ & $6 / 17(35 \%)^{\mathrm{b}}$ & $14 / 133(10 \%)^{\mathrm{b}}$ \\
$<15 \times 10^{9} / 1$ & $9 / 17(53 \%)$ & $110 / 133(83 \%)$ \\
Unknown & $2 / 17(12 \%)$ & $9 / 133(7 \%)$ \\
CRP & & \\
$<5$ mg/1 & $11 / 133(8 \%)$ \\
$>15$ mg/1 & & \\
$5-15$ mg/1 & & \\
Unknown & & \\
\hline
\end{tabular}

CDI: Clostridium difficile infection; ICU: intensive care unit; WBC: white blood cell count; CRP: C-reactive protein

${ }^{a}$ Including one patient with a positive PCR only

${ }^{\mathrm{b}} p<0.05$

treatment courses with antibiotics and recovered each time after the cessation of treatment.

To estimate the potential problem of asymptomatic carriage, PCR was performed in healthy volunteers. During a 2-month period, specimens were submitted by 141 unique volunteers. Of these, $30.5 \%$ were male, and the median age was 25 years (range 18-76). Most volunteers were students (49\%), followed by non-medical hospital employees $(27 \%)$, laboratory technicians (17\%), and physicians (7\%). TC, PCR, and CTT were positive in $1(0.7 \%)$ volunteer, and ICTAB was negative.

In our laboratory, unformed stool specimens are tested for C. difficile toxin at the doctor's request and if the patient has been admitted for $72 \mathrm{~h}$ or more. After implementation of the PCR in the routine laboratory, the percentage of patients 


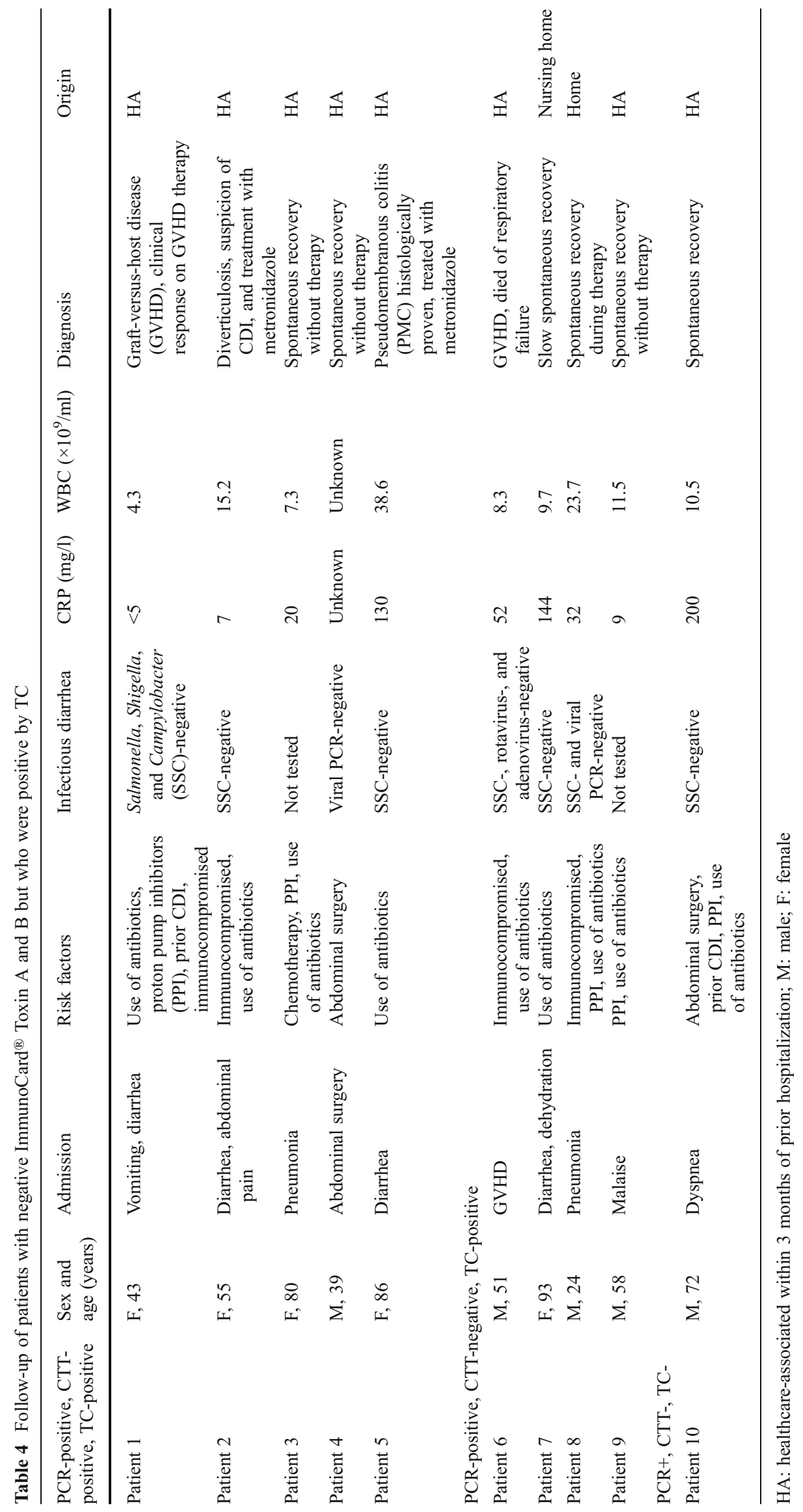


with positive results for $C$. difficile increased by more than 50\%. From 1 January 2010 until 30 June 2010, before implementation of the PCR, 895 stool specimens from 694 patients were tested and $7.3 \%$ of the specimens and $8.6 \%$ (60) of the patients were positive for $C$. difficile using ICTAB only. From 1 January 2011 until 30 June 2011, after implementation of the PCR, 809 stool specimens from 657 patients were tested and $12.7 \%$ of the specimens and $13.5 \%$ (89) of the patients were positive for $C$. difficile using the PCR only. Two of the 103 PCR-positive specimens were not available for culture. Of the remaining 101 specimens, all were confirmed by culture except for one.

\section{Discussion}

PCR is a sensitive and specific method for the detection of toxin-producing $C$. difficile. In this study, the sensitivity and specificity were 100 and $99 \%$, respectively, using TC as the gold standard, which is in keeping with previous studies [1]. CTT was positive in only $70 \%$ of the specimens with a positive TC and the EIAs used had a sensitivity of 47 and $58.8 \%$. The specificity of CTT, ICTAB, and ELISA were 100,99 , and $89 \%$, respectively. The low sensitivity of ICTAB could not be ascribed to the presence of difficultto-detect ribotypes as described previously; only 2 of the 9 false-negative were type 002 [17].

The interpretation of a positive TC and/or PCR result is difficult since asymptomatic carriage of $C$. difficile occurs frequently. In our study, TC/PCR as well as CTT was positive in only one of 141 healthy volunteers $(0.7 \%)$. Other studies have detected asymptomatic carriage of toxigenic $C$. difficile in healthy subjects of between 0.5 and $13 \%[18,19]$. Moreover, in hospitalized patients, carriage has been described in up to $14 \%[20,21]$. Therefore, the mere demonstration of $C$. difficile capable of producing toxin $\mathrm{A}$ and/or $\mathrm{B}$ does not necessarily mean that it is the causative agent of the clinical signs and symptoms in a patient [20].

Taking this relatively high occurrence of asymptomatic carriage into consideration, one could hypothesize that the demonstration of toxin activity directly in the stool by CTT may be more predictive for the presence of CDI. However, the CTT was also positive in the one healthy volunteer in this study, and in a study by Kyne et al., 79\% of 19 asymptomatic carriers had a positive CTT directly in stool [20].

The median $\mathrm{CT}$ value was higher in the patients with a negative CTT compared to the patients who were TC-, PCR-, and CTT-positive. However, in this small series, there was considerable overlap of CTs. It, therefore, does not seem to be helpful to determine the clinical significance in the individual patient.

In addition to the fact that laboratory tests cannot distinguish between infection and colonization, in many cases, a clinical diagnosis of CDI is complicated because hospitalized patients with diarrhea due to $C$. difficile share signs and symptoms with diarrhea due to other causes, especially antibiotic treatment itself. Indeed, in the patients included in this study, who were already identified to be at risk for CDI by the clinician, there were no significant differences between patients with and without a positive result for $C$. difficile with respect to clinical presentation, except for more prior antibiotic use and a higher WBC in patients with positive results. Even in retrospect, a clinical diagnosis of CDI was difficult to establish. Since the routine diagnosis of C. difficile in our laboratory was based solely on the ICTAB results and the other tests were done later in batch, we identified nine additional patients with positive TC, of whom five had a positive CTT and one patient with a negative TC and positive PCR. Review of their medical records showed that, in one patient with a positive CTT, a diagnosis of CDI was established by endoscopy and another patient with a positive CTT was successfully treated for CDI despite the negative routine results. On the other hand, symptoms resolved within 2 days in two patients with a positive CTT despite the continuation of antibiotics and one patient had a diagnosis of GVHD. Thus, except in one patient, CDI could not be proven, but it certainly could not be ruled out either since CDI may be self-limiting. Even the patient with an alternative diagnosis of GVHD may have had concurrent CDI. In the five patients who were positive by PCR and negative by CTT (one was also TC-negative), a clinical diagnosis of CDI could also not be established in retrospect: one was diagnosed with extensive GVHD and the other four patients recovered without intervention.

Community-acquired CDI and CDI in the absence of a history of antibiotic use are increasingly reported and will further complicate a clinical diagnosis of CDI in the future [22].

After substitution of ICTAB by the PCR in the routine clinical laboratory, the percentage of positive patients increased by more than $50 \%$, which confirms the high sensitivity of the PCR described in this study in a larger number of patients with 809 specimens from 657 patients tested, of which 103 specimens were positive. The specificity for the presence of toxigenic $C$. difficile in the stool was also confirmed, as 100 of the 101 PCR-positive specimens were confirmed by TC.

In conclusion, PCR for the detection of toxigenic $C$. difficile has a high sensitivity and can rule out CDI, but it cannot differentiate CDI from asymptomatic carriage. CTT does not seem to differentiate between infection and carriage either. Clinicians should be aware of the occurrence of asymptomatic carriage to prevent inappropriate administration of antibiotics or cessation of antibiotic therapy, and to prevent delay of other diagnostics or therapy. 
Acknowledgments We kindly thank E.J. Kuijper and I.M.J.G. Sanders of the National Reference Laboratory for Clostridium difficile, Leiden University Medical Center, Leiden, the Netherlands, for performing the ribotyping on all isolates.

Conflict of interest The authors declare that they have no conflict of interest.

Open Access This article is distributed under the terms of the Creative Commons Attribution License which permits any use, distribution, and reproduction in any medium, provided the original author(s) and the source are credited.

\section{References}

1. Cohen SH, Gerding DN, Johnson S, Kelly CP, Loo VG, McDonald LC, Pepin J, Wilcox MH; Society for Healthcare Epidemiology of America; Infectious Diseases Society of America (2010) Clinical practice guidelines for Clostridium difficile infection in adults: 2010 update by the Society for Healthcare Epidemiology of America (SHEA) and the Infectious Diseases Society of America (IDSA). Infect Control Hosp Epidemiol 31:431-455

2. Barbut F, Delmée M, Brazier JS, Petit JC, Poxton IR, Rupnik M, Lalande V, Schneider C, Mastrantonio P, Alonso R, Kuipjer E, Tvede M; ESCMID Study Group on Clostridium difficile (ESGCD) (2003) A European survey of diagnostic methods and testing protocols for Clostridium difficile. Clin Microbiol Infect 9:989-996

3. Barbut F, Braun M, Burghoffer B, Lalande V, Eckert C (2009) Rapid detection of toxigenic strains of Clostridium difficile in diarrheal stools by real-time PCR. J Clin Microbiol 47:1276-1277

4. Peterson LR, Manson RU, Paule SM, Hacek DM, Robicsek A, Thomson RB Jr, Kaul KL (2007) Detection of toxigenic Clostridium difficile in stool samples by real-time polymerase chain reaction for the diagnosis of $C$. difficile-associated diarrhea. Clin Infect Dis 45:1152-1160

5. Sloan LM, Duresko BJ, Gustafson DR, Rosenblatt JE (2008) Comparison of real-time PCR for detection of the $t c d C$ gene with four toxin immunoassays and culture in diagnosis of Clostridium difficile infection. J Clin Microbiol 46:1996-2001

6. Alcalá L, Sánchez-Cambronero L, Catalán MP, Sánchez-Somolinos M, Peláez MT, Marín M, Bouza E (2008) Comparison of three commercial methods for rapid detection of Clostridium difficile toxins A and B from fecal specimens. J Clin Microbiol 46:3833-3835

7. Planche T, Aghaizu A, Holliman R, Riley P, Poloniecki J, Breathnach A, Krishna S (2008) Diagnosis of Clostridium difficile infection by toxin detection kits: a systematic review. Lancet Infect Dis 8:777-784

8. Vanpoucke H, De Baere T, Claeys G, Vaneechoutte M, Verschraegen $\mathrm{G}$ (2001) Evaluation of six commercial assays for the rapid detection of Clostridium difficile toxin and/or antigen in stool specimens. Clin Microbiol Infect 7:55-64

9. Eastwood K, Else P, Charlett A, Wilcox M (2009) Comparison of nine commercially available Clostridium difficile toxin detection assays, a real-time PCR assay for $C$. difficile $t c d B$, and a glutamate dehydrogenase detection assay to cytotoxin testing and cytotoxigenic culture methods. J Clin Microbiol 47:3211-3217

10. van den Berg RJ, Vaessen N, Endtz HP, Schülin T, van der Vorm ER, Kuijper EJ (2007) Evaluation of real-time PCR and conventional diagnostic methods for the detection of Clostridium difficileassociated diarrhoea in a prospective multicentre study. J Med Microbiol 56:36-42

11. van den Berg RJ, Kuijper EJ, van Coppenraet LE, Claas EC (2006) Rapid diagnosis of toxinogenic Clostridium difficile in faecal samples with internally controlled real-time PCR. Clin Microbiol Infect $12: 184-186$

12. van den Berg RJ, Bruijnesteijn van Coppenraet LS, Gerritsen HJ, Endtz HP, van der Vorm ER, Kuijper EJ (2005) Prospective multicenter evaluation of a new immunoassay and real-time PCR for rapid diagnosis of Clostridium difficile-associated diarrhea in hospitalized patients. J Clin Microbiol 43:5338-5340

13. Stamper PD, Alcabasa R, Aird D, Babiker W, Wehrlin J, Ikpeama I, Carroll KC (2009) Comparison of a commercial real-time PCR assay for $t c d B$ detection to a cell culture cytotoxicity assay and toxigenic culture for direct detection of toxin-producing Clostridium difficile in clinical samples. J Clin Microbiol 47:373-378

14. Weisburg WG, Barns SM, Pelletier DA, Lane DJ (1991) 16S ribosomal DNA amplification for phylogenetic study. J Bacteriol 173:697-703

15. van Doornum GJ, Guldemeester J, Osterhaus AD, Niesters HG (2003) Diagnosing herpesvirus infections by real-time amplification and rapid culture. J Clin Microbiol 41:576-580

16. Bélanger SD, Boissinot M, Clairoux N, Picard FJ, Bergeron MG (2003) Rapid detection of Clostridium difficile in feces by realtime PCR. J Clin Microbiol 41:730-734

17. Tenover FC, Novak-Weekley S, Woods CW, Peterson LR, Davis T, Schreckenberger P, Fang FC, Dascal A, Gerding DN, Nomura JH, Goering RV, Akerlund T, Weissfeld AS, Baron EJ, Wong E, Marlowe EM, Whitmore J, Persing DH (2010) Impact of strain type on detection of toxigenic Clostridium difficile: comparison of molecular diagnostic and enzyme immunoassay approaches. J Clin Microbiol 48:3719-3724

18. Kato H, Kita H, Karasawa T, Maegawa T, Koino Y, Takakuwa H, Saikai T, Kobayashi K, Yamagishi T, Nakamura S (2001) Colonisation and transmission of Clostridium difficile in healthy individuals examined by PCR ribotyping and pulsed-field gel electrophoresis. J Med Microbiol 50:720-727

19. Ryan J, Murphy C, Twomey C, Paul Ross R, Rea MC, Macsharry J, Sheil B, Shanahan F (2009) Asymptomatic carriage of Clostridium difficile in an Irish continuing care institution for the elderly: prevalence and characteristics. Ir J Med Sci 179:245-250

20. Kyne L, Warny M, Qamar A, Kelly CP (2000) Asymptomatic carriage of Clostridium difficile and serum levels of IgG antibody against toxin A. N Engl J Med 342:390-397

21. Shim JK, Johnson S, Samore MH, Bliss DZ, Gerding DN (1998) Primary symptomless colonisation by Clostridium difficile and decreased risk of subsequent diarrhoea. Lancet 351:633-636

22. Pituch H (2009) Clostridium difficile is no longer just a nosocomial infection or an infection of adults. Int J Antimicrob Agents 33 (Suppl 1):S42-S45 